\title{
Thermophysics of metal alkanoates VII. Heat capacities and thermodynamic properties of potassium n-butanoate ${ }^{a}$
}

\author{
P. FRANZOSINI, $\dagger$
}

C.N.R. c/o Dipartimento di Chimica Fisica. Universita di Pavia. Viale Taramelli 16. I-27100 Pavia, Italy

S. P. NGEYI, and E. F. WESTRUM, JR.

Department of Chemistry, University of Michigan. An Arbor, Michigan 48109, U.S.A.

(Received 18 April 1986)

\begin{abstract}
The subambient heat-capacity curve of potassium $n$-butanoate as determined by adiabatic equilibrium calorimetry is characterized by a "bifurcated" transition whose "peaks" occur at 123.85 and $142.3 \mathrm{~K}$. The corresponding $\left(\dot{C}_{\mathrm{p} . \mathrm{m}} / R\right)_{\max }, \Delta_{\mathrm{trs}} H_{\mathrm{m}}^{\circ} / R$, and $\Delta_{\mathrm{trs}} S_{\mathrm{m}}^{\nu} / R$ values are 24.1 . $23.85 ; 49.3 \mathrm{~K}, 32.5 \mathrm{~K}$; and $0.400,0.226$, respectively. Smoothed thermodynamic functions are provided in tabular form from 10 to $350 \mathrm{~K}$.
\end{abstract}

\section{Introduction}

Information (obtained by equilibrium adiabatic calorimetry) was provided in Papers III ${ }^{(1)}$ and IV $^{(2)}$ of this series on the molar heat capacities (and relevant thermodynamic functions) of potassium propanoate and isobutanoate, respectively. in the temperature range between 5 and $350 \mathrm{~K}$. Investigation is now extended to n-butanoate because of its peculiar thermophysical behavior which makes it a quite special member of the potassium $n$-alkanoate family.

Superambient d.s.c. results reported previously by one of $u^{(3.6)}$ on transition (trs), fusion (fus), and clearing (clr) temperatures and molar enthalpy changes for the sequence; potassium methanoate $\left(n_{\mathrm{C}}=1 ; n_{\mathrm{C}}\right.$ : number of carbon atoms), ... $n$-eicosanoate $\left(n_{\mathrm{C}}=20\right)$ are shown in figure 1 , where the sets of entropy changes specified below are plotted against $n_{\mathrm{C}}$ for $1 \leqslant n_{\mathrm{C}} \leqslant 15$.

In figure $1 \bigcirc$ represents $\Delta_{\mathrm{fus}} S_{\mathrm{m}} / R$, and $T_{\mathrm{fus}}$ is identified as the temperature at which one of the following transformations occurs:

$$
\begin{array}{ll}
\text { Crystal }=\text { isotropic liquid } & \text { (for } \left.1 \leqslant n_{C} \leqslant 3\right) ; \\
\text { Crystal }=\text { liquid crystal } & \left(\text { for } 4 \leqslant n_{C} \leqslant 8\right) ; \\
\text { Plastic crystal }- \text { liquid crystal } & \left(\text { for } 9 \leqslant n_{C} \leqslant 15\right) .
\end{array}
$$

"The first paper in this series is reference 12 .

+ Died 24 January 1986. 


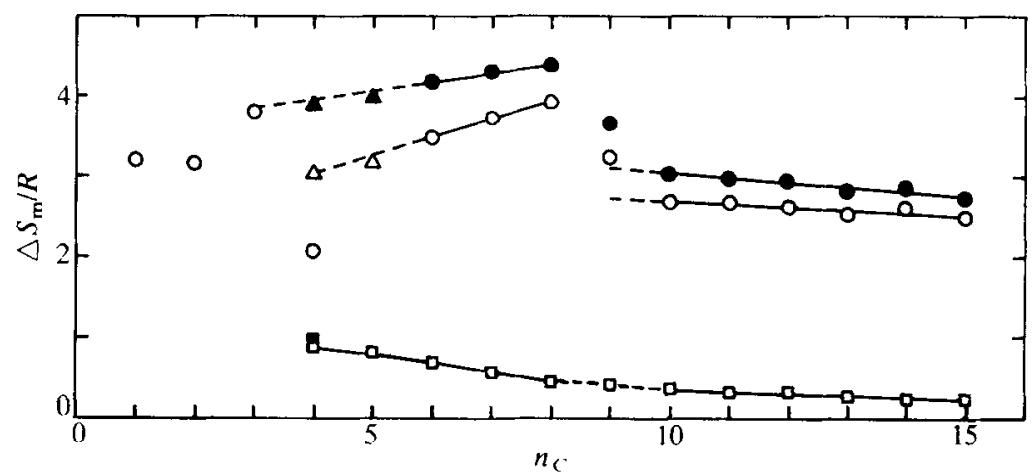

FIGURE 1. Entropy changes involved in various phase transformation of the potassium $n$-alkanoates with $1 \leqslant n_{\mathrm{C}} \leqslant 15 . \square$, Clearing; 0 . fusion; $\boldsymbol{\Delta}, \mathbf{O}$, summation of values for fusion and for clearing (see the text).

Among the $\Delta_{\mathrm{fus}} S_{\mathrm{m}}^{\circ} / R \mathrm{~s}$ no correlation is apparent for $1 \leqslant n_{\mathrm{c}} \leqslant 4$, whereas linear correlations exist, on the one hand, for $6 \leqslant n_{\mathrm{C}} \leqslant 8$, and, on the other hand, for $10 \leqslant n_{\mathrm{C}} \leqslant 15$. This indicates that each of these two groups of homologs probably has related, though different, fusion processes.

$\Delta_{\mathrm{fus}} S_{\mathrm{m}}^{\circ} / R$ for $n_{\mathrm{C}}=5$ is not known, inasmuch as transformational enthalpy increments for fusion and a close-to-fusion transition could not be resolved. ${ }^{(5)}$

The $\Delta_{\text {fus }} / S_{\mathrm{m}}^{\circ} / R$ break between $n_{\mathrm{C}}=8$ and $n_{\mathrm{C}}=9$ is due to the change of the fusion process consequent on the formation of plastic crystalline phases at $n_{\mathrm{C}}=9$. The value for $n_{\mathrm{C}}=9^{(4)}$ was probably overestimated, because of the difficulty of an accurate evaluation occasioned by partial overlapping (in the recorded d.s.c. traces) of the (crystal = plastic crystal) "hump" and the fusion "peak": this value, if correctly measured, would probably lie on the extension to lower $n_{\mathrm{C}}$ of the $\Delta_{\mathrm{fus}} S_{\mathrm{m}}^{\circ} / R$ curve for $10 \leqslant n_{\mathrm{C}} \leqslant 15$.

The lowest $\Delta_{\text {fus }} S_{\mathrm{m}}^{\circ} / R$ value of the sequence is that shown by the $n$-butanoate.

Visual polythermal observations allowed Sokolov, ${ }^{(7)}$ and Sokolov and Pochtakova $^{(8)}$ to claim for potassium $n$-butanoate the following phase transformations in the superambient region:

$$
\begin{aligned}
& \text { Crystal III } \underset{(463 \pm 1) \mathrm{K}}{\stackrel{T_{111-11}}{\rightleftarrows}} \longrightarrow \text { crystal II } \underset{(555.5 \pm 2.5) \mathrm{K}}{\stackrel{T_{11-1}}{\rightleftarrows}} \text { crystal I }
\end{aligned}
$$

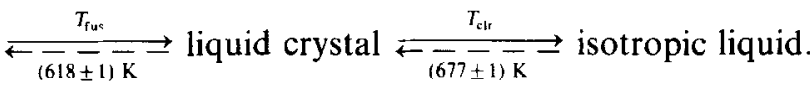

To avoid confusion, the nomenclature adopted in scheme (1) is that which we employ usually; in the original papers, however, the transformations at $(618 \pm 1)$ and $(677 \pm 1) \mathrm{K}$ had been designated as a "transition" and "fusion", respectively.

Later the (superambient) phase relations listed in table 1 were obtained by d.s.c. ${ }^{(3)}$ These differ from those reported elsewhere in that d.s.c. proved that both of the solid-state transformations mentioned by the Russian authors ${ }^{(7,8)}$ are actually 
TABLE 1. Superambient phase transformations (trf) of potassium $n$-butanoate as detected by d.s.c. ${ }^{(3)}$

\begin{tabular}{lccc}
\hline \multicolumn{1}{c}{ trf } & \multicolumn{1}{c}{$T_{\mathrm{trf}} / \mathrm{K}$} & $\left\langle T_{\mathrm{rrf}}\right\rangle / \mathrm{K}$ & $\Delta_{\mathrm{rff}} S_{\mathrm{m}} / R$ \\
$\mathrm{clr}$ & $677.3 \pm 0.5$ & - & 0.38 \\
fus & $\{26.1 \pm 0.5$ & - & 2.08 \\
$\mathrm{II} \rightarrow \mathrm{I}^{a}$ & $\left\{\begin{array}{l}562.2 \pm 0.5 \\
541 \pm 1\end{array}\right.$ & $552 \pm 1$ & $0.97^{b}$ \\
$\mathrm{III} \rightarrow \mathrm{II}^{a}$ & $\left\{\begin{array}{l}467.2 \pm 0.5 \\
461.4 \pm 0.5\end{array}\right.$ & $464.3 \pm 0.5$ & $0.30^{b}$ \\
\hline
\end{tabular}

“Twin transformation (for explanation, see text).

' Cumulative value.

split into two component peaks. Accordingly, scheme (1) should be modified as follows:

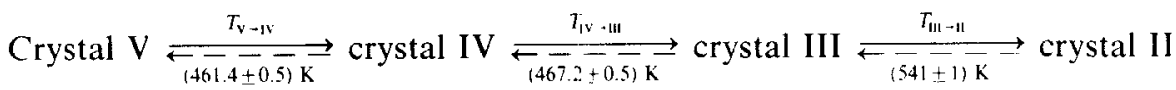

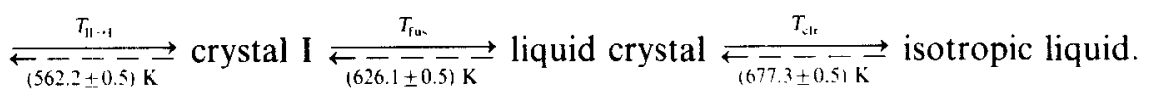

This splitting, which represents another characteristic feature of potassium $n$-butanoate, was confirmed by subsequent a.c. conductance measurements by Schiraldi and Chiodelli. ${ }^{(9)}$ For each bifurcated couple, however, only a cumulative enthalpy change, $\left(\Delta_{\mathrm{trs}} H_{\mathrm{m}}^{\circ}\right)_{\mathrm{cum}}$, could be measured by d.s.c. because of overlapping (particularly large in the case of the couple at lower temperature) and, accordingly. only a cumulative entropy contribution $\Delta_{\mathrm{trs}} S_{\mathrm{m} \text {, cum }}=\Delta_{\mathrm{trs}} H_{\mathrm{m} \text {. cum }} /\left\langle T_{\mathrm{rrs}}\right\rangle$ i where $\left\langle T_{\text {trs }}\right\rangle=\left(\left\langle T_{\text {trs. } 1}\right\rangle+T_{\text {trs. } 2}\right) / 2$, and $T_{\text {trs, } 1}, T_{\text {trs. } 2}$ refer to component peaks 1,2 of the couple, respectively\} could be calculated. (For simplicity, only $\left\langle T_{\mathrm{rrs}}\right\rangle$ values were quoted in Paper IV ${ }^{(2)}$ of this series, and phase designation was made accordingly.)

It is worth noting that for $n-\mathrm{CH}_{3}\left(\mathrm{CH}_{2}\right)_{2} \mathrm{CO}_{2} \mathrm{~K}$, summation of d.s.c. $\Delta_{\mathrm{trs}} S_{\mathrm{m} \text {. cum. III } \rightarrow \mathrm{II}+\mathrm{II} \rightarrow \mathrm{I}}$ (represented by a filled square in figure 1) plus $\Delta_{\mathrm{fus}} S_{\mathrm{m}}$ provides a value which lies on the extension of $\Delta_{\mathrm{fus}} S_{\mathrm{m}}^{\circ}$ curve for $6 \leqslant n_{\mathrm{C}} \leqslant 8$ in figurc 1 , as does the $\left(\Delta_{\mathrm{fus}} S_{\mathrm{m}}^{\circ}+\Delta_{\mathrm{trs}} S_{\mathrm{m}}^{\circ}\right)$ value \{relevant to fusion + the close-to-fusion transition mentioned above\} for $n-\mathrm{CH}_{3}\left(\mathrm{CH}_{2}\right)_{2} \mathrm{CO}_{2} \mathrm{~K}$; both values are represented by open triangles in the figure.

Finally, $n$-butanoate is the shortest member of the potassium n-alkanoate family which can cxist as a mesomorphic liquid, and, at the same time, the homolog exhibiting the largest $\Delta_{\mathrm{clr}} S_{\mathrm{m}}$ and the smallest $\Delta_{\mathrm{fus}} S_{\mathrm{m}}$. The open squares represent in figure 1 the clearing entropies of the sequence $n$-butanoate, $\cdots, n$-pentadecanoate. The clearing mechanism can be reasonably assumed to be the same from $n_{\mathrm{C}}$ of 4 through 15: consequently, a single slightly curved line can be used to represent the corresponding $\Delta_{\mathrm{clr}} S_{\mathrm{m}}^{\circ}$ values. For the present purposes (summation; see below), separate linear interpolation for $6 \leqslant n_{\mathrm{C}} \leqslant 8$, and $10 \leqslant n_{\mathrm{C}} \leqslant 15$ is an alternative.

Summation of $\Delta_{\mathrm{fus}} S_{\mathrm{m}}^{\circ}$ and $\Delta_{\mathrm{clr}} S_{\mathrm{m}}^{\circ}$ values yields $\Delta_{\Sigma \text { trf }} S_{\mathrm{m}}^{\circ}$ values. On the extension of the $\Delta_{\Sigma \text { trf }} S_{\mathrm{m}}^{\circ}$ curve relevant to $6 \leqslant n_{\mathrm{C}} \leqslant 8$ lie: (a) the values (represented by filled triangles) obtained by adding to the corresponding open triangles (lying in turn on 
the extension of the $\Delta_{\text {fus }} S_{\mathrm{m}}$ line) the clearing entropies pertaining to $n$-butanoate and $n$-pentanoate, respectively; and (b) the fusion entropy of the propanoate. This, on the one hand, allows one to conclude that (analogously to what we found previously $^{(10)}$ in the lithium family) the sequence starting with propanoate metastable for lithium and ending with the longest homolog unable to form plastic crystals (i.e. either $n$-hendecanoate or $n$-octanoate when the cation is either Li or K. respectively) have correlated fusion mechanisms; and - on the other hand offers an interesting example of "stepwise fusion". Indeed, for each homolog with $3 \leqslant n_{\mathrm{C}} \leqslant 8$ transformation into a clear melt of the crystalline phase stable around $500 \mathrm{~K}$ occurs, with an overall entropy variation $\Delta_{\Sigma \mathrm{rrf}} S_{\mathrm{m}}^{\circ}$ almost linearly depending on $n_{\mathrm{C}}$, in a single step (i.e. crystal I $\rightarrow$ isotropic liquid) when $n_{\mathrm{C}}=3$, in four steps (i.e. crystal III $\rightarrow$ crystal II; crystal II $\rightarrow$ crystal I; crystal I $\rightarrow$ liquid crystal; and liquid crystal $\rightarrow$ isotropic liquid) when $n_{\mathrm{C}}=4$, in three steps (i.e. crystal II $\rightarrow$ crystal I; crystal I $\rightarrow$ liquid crystal; and liquid crystal $\rightarrow$ isotropic liquid) when $n_{C}=5$, and in two steps (i.e. crystal $\mathrm{I} \rightarrow$ liquid crystal, and liquid crystal $\rightarrow$ isotropic liquid) when $n_{\mathrm{C}}=6,7,8$.

In the sub-ambient region (down to $110 \mathrm{~K}$ ), the only information available prior to the present study is that partially overlapping peaks occur in d.s.c. traces at $(123 \pm 2)$ and $(143 \pm 2) \mathrm{K},{ }^{(3)}$ with a cumulative entropy variation $\Delta_{\mathrm{trs}} S_{\mathrm{m} \text {, cum }}^{\circ} \approx 0.6 R$.

The present paper reports on a detailed equilibrium adiabatic-calorimetric study of $n-\mathrm{CH}_{3}\left(\mathrm{CH}_{2}\right)_{2} \mathrm{CO}_{2} \mathrm{~K}$ in the temperature region below $350 \mathrm{~K}$, whereas investigation at higher temperatures will be completed subsequently.

\section{Experimental}

The potassium $n$-butanoate used in this study was prepared by reacting (in anhyrous methanol) Fluka puriss p.a. $\mathrm{K}_{2} \mathrm{CO}_{3}$ with (5 per cent excess over stoichiometry) Fluka puriss ( $\geqslant 99$ per cent: tested at the source by g.c.) $n$-butanoic acid. The solid recovered after evaporation to incipient crystallization in a Rotavapor device under reduced pressure and subsequent cooling was further purified by repeated crystallization from anhydrous ethanol. After drying under vacuum at a temperature intermediate between $T_{11 \rightarrow 1}$ and $T_{\text {fus }}$, the sample was submitted to d.s.c. analysis in the superambient region: fair agreement was obtained between the traces recorded here and the values of $T_{\mathrm{trs}}, T_{\mathrm{fus}}$, and $T_{\mathrm{clr}}$ listed in table 1 .

The salt was loaded into a gold-plated OFHC copper calorimeter, laboratory designation $\mathrm{W}-62$, and the determinations were made in the Mark X cryostat described elsewhere. (11) Data logging, calorimetry, and programming were computer assisted. ${ }^{(12)}$

Two separate loadings were made of this sample because an instrumental problem resulted in the melting of a Cerroseal-soldered seam of the calorimeter. Approximately $60 \mathrm{~d}$ between the loadings permitted complete diagnosis and repair of the instrument. The mass of the sample used during the first loading was $24.000 \mathrm{~g}$ (corresponding to $0.19017 \mathrm{~mol}$; molar mass: $126.201 \mathrm{~g} \cdot \mathrm{mol}^{-1}$, on the basis of the 1978 IUPAC relative atomic masses), that during the second loading $20.975 \mathrm{~g}$ ( $\triangleq 0.16620 \mathrm{~mol}$ ). The buoyancy corrections were calculated using a density of 
$1.21 \mathrm{~g} \cdot \mathrm{cm}^{-3}$. The pressures of purified helium admitted into the (previously evacuated) calorimeter during the first and second loading, to promote thermal equilibrium, were 3.39 and $3.60 \mathrm{kPa}$ (at room temperature), respectively.

The heat capacity of the second loaded sample was 84 per cent of the total (sample + calorimeter) heat capacity at $10 \mathrm{~K}$ and decreased to 55 to 60 per cent above $115 \mathrm{~K}$ except in the transition region.

The thermal history outlined below in linear array shows the details of the thermal cycles to which the sample was subjected: the unbroken arrows show cooling periods while dashed arrows show periods of acquisition of results. First loading:

$$
297.5 \mathrm{~K} \stackrel{12 \mathrm{~h}}{\longrightarrow} 161 \mathrm{~K}-\frac{13.3 \mathrm{~h}}{\text { Series } \mathrm{l}} \rightarrow 350 \mathrm{~K} \stackrel{12 \mathrm{~h}}{\longrightarrow} 141 \mathrm{~K} \underset{\text { no results }}{-} \underset{\text { taken }}{\rightarrow} 298 \mathrm{~K}
$$

Second loading (after $64 \mathrm{~d}$ at $298 \mathrm{~K}$ ):

$$
\begin{aligned}
& 298 \mathrm{~K} \stackrel{16 \mathrm{~h}}{\longrightarrow} 186 \mathrm{~K}-\frac{12.5 \mathrm{~h}}{\text { Series II }} \rightarrow 346 \mathrm{~K} \stackrel{16 \mathrm{~h}}{\longrightarrow} 103 \mathrm{~K} \stackrel{8 \mathrm{~h}}{\text { Series III }} 212 \mathrm{~K} \\
& \stackrel{13 \mathrm{~h}}{\longrightarrow} 63 \mathrm{~K} \underset{\text { Series } \mathrm{NV}}{\stackrel{7 \mathrm{~h}}{\longrightarrow}} 157 \mathrm{~K} \longrightarrow \stackrel{18 \mathrm{~h}}{\longrightarrow} 110 \mathrm{~K}
\end{aligned}
$$

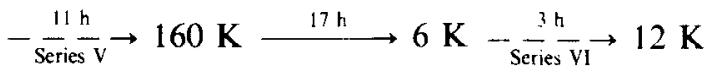

$$
\begin{aligned}
& \stackrel{0.5 \mathrm{~h}}{\longrightarrow} 6.8 \mathrm{~K} \underset{\text { Series }}{-\frac{14 \mathrm{~h}}{\mathrm{III}}} \rightarrow 72 \mathrm{~K} \stackrel{54 \mathrm{~h}}{\longrightarrow} 63 \mathrm{~K} \underset{\text { Serres }}{\stackrel{15.5 \mathrm{~h}}{\mathrm{~V}} \rightarrow 1} \rightarrow 152 \mathrm{~K} .
\end{aligned}
$$

\section{Results and discussion}

The dimensionless ratios $C_{p, \mathrm{~m}} / R$ (at the mean temperature of each measurement) are listed in table 2 in chronological sequence by series. The results obtained from the first loading at $161 \leqslant T / \mathrm{K} \leqslant 350$ are shown in this table as Series I. Repeated determinations over the same temperature interval were made for the second loading, and the relevant results were employed to obtain the thermodynamic functions in this interval since the same calorimeter was used (after repair) for the lower-temperature regions. The standard deviation of the heat capacities from the second loading was 5 per cent at $6 \mathrm{~K}, 0.3$ per cent at $20 \mathrm{~K}$, and less than 0.1 per cent at temperatures above $50 \mathrm{~K}$.

The overall plot of $C_{p, m} / R$ against $T$ is shown in figure 2 . An expanded section which highlights the features of the curve between 100 and $160 \mathrm{~K}$ is depicted in figure 3 .

From figure 2 it can be seen clearly that the peaks, essentially non-isothermal but predominantly first-order transformations, are followed by a diffuse anomaly (so diffused and flattened that no reliable evaluation of the entropy change involved is possible) in the heat-capacity curve. This is probably some kind of gradual (probably higher-order) transformation with maximum height at about $250 \mathrm{~K}$. Such behavior is consistent with the characteristics of carboxylic-acid salts of alkali 
TABLE 2. Experimental heat capacities of potassium $n$-butanoate $\left(R=8.3144 \mathrm{~J} \cdot \mathrm{K}^{-1} \cdot \mathrm{mol}^{\prime}\right)$

\begin{tabular}{|c|c|c|c|c|c|c|c|c|c|c|c|}
\hline$T / \mathbf{K}$ & $C_{p, m} / R$ & $T / \mathrm{K}$ & $C_{p, \mathrm{~m}} / R$ & $T / \mathrm{K}$ & $C_{p, m} / R$ & $T / \mathrm{K}$ & $C_{p_{r} \mathrm{~m}} / R$ & $T / \mathbf{K}$ & $C_{p, \mathrm{~m}} / R$ & $T / \mathrm{K}$ & $C_{D, \mathrm{~m}} / R$ \\
\hline Ser & ies I & 7.62 & .853 & 6.79 & 15.419 & 121.48 & 6.7 & 9.73 & 0.2 & Series & s VIII \\
\hline$\Delta H_{\mathrm{m}}$ & Detn. A & 212.74 & & & & & & 10.33 & & 68.39 & 7.577 \\
\hline & & 17.89 & 16.259 & 158.81 & & 124.57 & & 10.95 & & & \\
\hline 20 & 15 & & & & & & & & & & \\
\hline & 16.0 & & & & & & & 12.21 & & 19.93 & 3.308 \\
\hline & & & & & & & & & & & \\
\hline & 16.4 & & 17.324 & 181.35 & 14.8 & 131.41 & & 13.49 & & 21.08 & 14.464 \\
\hline & 16.6 & 8.98 & 17.518 & 186.99 & 15.0 & 133.70 & & & & & \\
\hline & & & & & & & & & & & 941 \\
\hline & & .29 & & 198. & & & & & & & \\
\hline & 17.3 & & & 203.93 & & & & & & & 8.403 \\
\hline & 17.4 & & 18.279 & 209.59 & 15.991 & 144.27 & & 18.11 & 1.044 & & 19.416 \\
\hline & 17.714 & 4.80 & 18.430 & es & s IV & 145. & & & & & 0.363 \\
\hline 259.27 & 17.896 & 79.98 & 18.561 & & & 147.00 & & 20.79 & & & 073 \\
\hline & & 5.16 & 18.614 & 65.63 & 7.29 & 18.27 & & 22 & & & \\
\hline & 18.1 & & & & & & & & & & 9.671 \\
\hline & & 93.42 & 18.783 & 74.01 & 8.11 & 151.71 & & 24.89 & 1,9 & & 836 \\
\hline & & & & & & & & & & 125.38 & 17.287 \\
\hline & 18.5 & & 19.295 & 81.90 & 8.89 & 157.90 & 13.826 & 8.58 & 2.4 & 131.55 & 13.886 \\
\hline 290.2 & 18.65 & 1.99 & 19.6 & & & \multirow{2}{*}{\multicolumn{2}{|c|}{ Series V }} & & & & \\
\hline 295.45 & 18.781 & & & .59 & 9.765 & & & 32.58 & 3.0 & 9.50 & 13.887 \\
\hline 300.62 & 18.980 & 324.77 & 20.088 & 96.74 & 10.172 & 8.054 & 0.1 & 34.61 & 3.29. & & .533 \\
\hline & 19.2 & & & & & & & & & 140.31 & 340 \\
\hline & 19.39 & 337.55 & 20.633 & 107.12 & 11.0 & 9.061 & 0.1 & 40.27 & 4.0 & 140.70 & 15.419 \\
\hline 316.09 & 19.606 & 343.94 & 20.932 & 112.32 & 11.472 & & & & & & \\
\hline 321.25 & 19.779 & \multirow{2}{*}{\multicolumn{2}{|c|}{ es III }} & & & 10.1 & & & & 41 & 18. \\
\hline 326.41 & 20.008 & & & $\Delta_{\mathrm{trs}} H_{\mathrm{m}}$ & & 10.68 & 0.2 & 49.69 & 5.36 & 141.74 & 19.783 \\
\hline & 20.287 & & & 153.80 & & & & & & & \\
\hline & 20.468 & & & 155.92 & 13.72 & 11.77 & 0.38 & 57.48 & & 142.35 & 21.767 \\
\hline 341.88 & 20.673 & 119.17 & 13.516 & & & & 6163 & & & \\
\hline 347.03 & 20.892 & & 19.109 & & & & & & & & 15.773 \\
\hline \multicolumn{2}{|c|}{ Series II } & & & & 11.3 & & & 70.03 & 7.739 & & \\
\hline \multicolumn{2}{|c|}{$\Delta H_{\mathrm{m}}$ Detn. B } & 141.30 & 18.123 & 118.50 & 12.795 & 9.10 & 0.195 & & & & \\
\hline
\end{tabular}

metals: comparable situations, observed in lithium homologs, have already been discussed elsewhere. ${ }^{(10,13)}$

However, when $n-\mathrm{CH}_{3}\left(\mathrm{CH}_{2}\right)_{2} \mathrm{CO}_{2}^{-}$is the anion, substitution of potassium for lithium as the cation causes dramatic changes in the thermal properties of the salt (e.g. the presence only of gradual solid-state transitions, and direct melting of the crystal into an isotropic liquid with lithium; presence of discontinuous, in the peculiar bifurcated mode, as well as of gradual transformations, and liquid crystal formation with potassium). Indeed, for $n-\mathrm{CH}_{3}\left(\mathrm{CH}_{2}\right)_{2} \mathrm{CO}_{2}^{-}$(which is the shortest flexible carboxylate anion), paramount importance probably ought to be attached to Michels and Ubbelohde's remark:(14) "for any given carboxylate anion, contact packings of oxygen atoms of the carboxy-group around an alkali cation seem to depend in a rather sensitive way not only on the cation repulsion radius, but also on the cation polarizability". We hope to be able to comment further on 


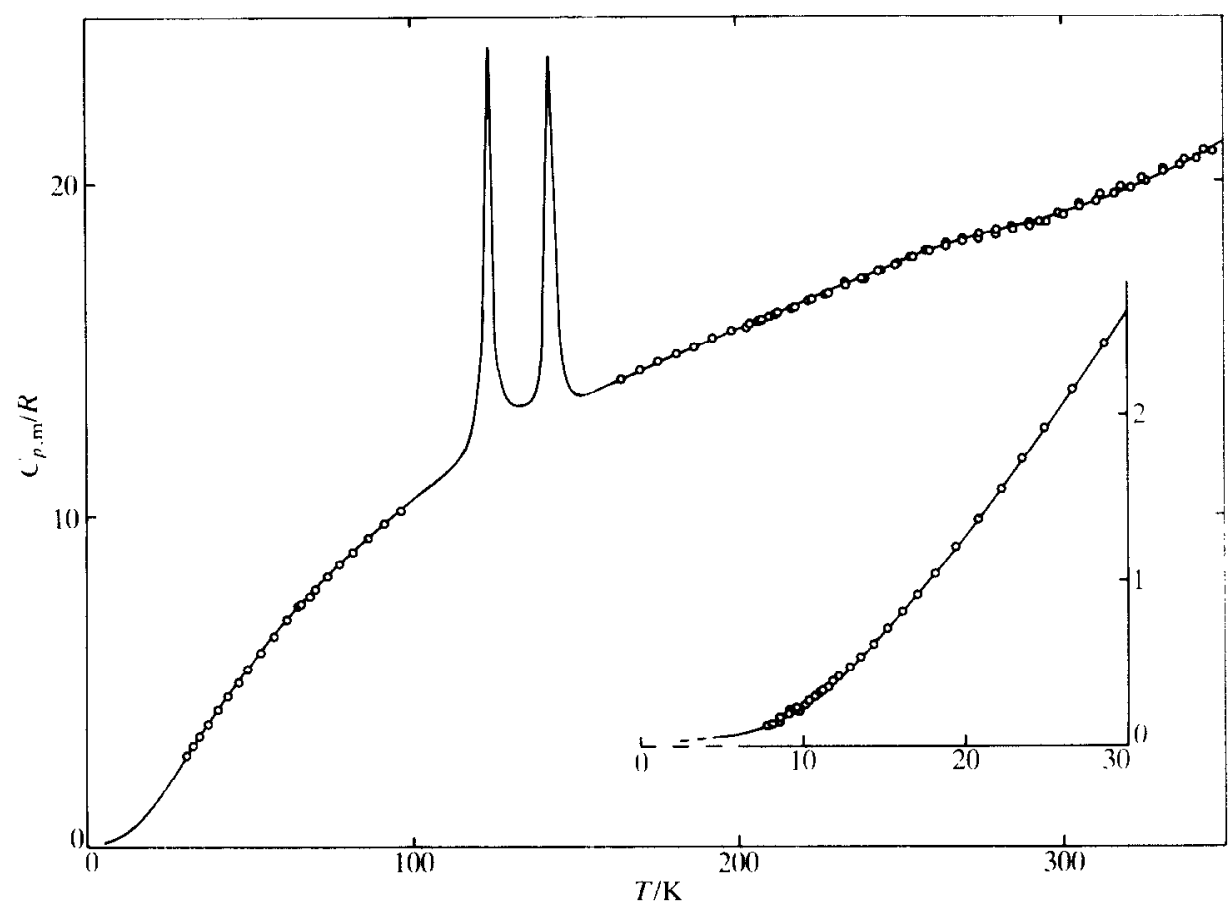

FIGURE 2. Experimental heat capacities of potassium n-butanoate taken in the Mark X cryostat below $350 \mathrm{~K}$. The interval between 100 and $160 \mathrm{~K}$ (which includes the IV $\rightarrow$ III transition region) is magnified in figure 3 .

TABLE 3. Enthalpy and entropy of $123.85 \mathrm{~K}$ transition in potassium $n$-butanoate $\left(R=8.3144 \mathrm{~J} \cdot \mathrm{K}^{-1} \cdot \mathrm{mol}^{-1}\right) ; N$ denotes the number of determintions

\begin{tabular}{|c|c|c|c|c|c|c|}
\hline & $N$ & $T_{1} / \mathrm{K}$ & $T_{2} / \mathrm{K}$ & $\Delta_{T !}^{T_{1}^{2}} H_{\mathrm{m}} /(R \cdot \mathrm{K})$ & $\Delta_{110 \mathrm{~K}}^{135 \mathrm{~K}} H_{\mathrm{m}} /(R$ & $\cdot \mathrm{K}) \Delta_{110 \mathrm{~K}}^{135 \mathrm{~K}} S_{\mathrm{m}} / R$ \\
\hline \multicolumn{7}{|c|}{ III $\rightarrow$ II Transition $(123.85 \mathrm{~K})$} \\
\hline Series III & 4 & 111.13 & 133.19 & 317.51 & 355.8 & \\
\hline Series IV & 2 & 109.71 & 129.69 & 288.29 & 356.2 & \\
\hline Series V & 11 & 110.45 & 134.84 & 346.61 & 355.2 & \\
\hline Series VIII & 16 & 113.60 & 137.22 & 342.76 & 355.3 & \\
\hline \multicolumn{5}{|c|}{ Graphical integration } & $355.5^{\circ}$ & 2.901 \\
\hline \multicolumn{4}{|c|}{ Lattice contribution (estimated) } & mean: & $\begin{array}{r}355.6 \\
-306.3 \\
\end{array}$ & 2.501 \\
\hline \multirow{2}{*}{\multicolumn{3}{|c|}{ Graphical integration }} & & $\begin{array}{l}\Delta_{\mathrm{trs}} H_{m} /(R \cdot \mathrm{K})= \\
\Delta_{\mathrm{trs}} S_{\mathrm{m}} / R\end{array}$ & 49.3 & \multirow[t]{2}{*}{0.400} \\
\hline & & & & $\Delta_{\mathrm{trs}} H_{\mathrm{m}} / R$ & 49.24 & \\
\hline
\end{tabular}

"Not included in mean value. 


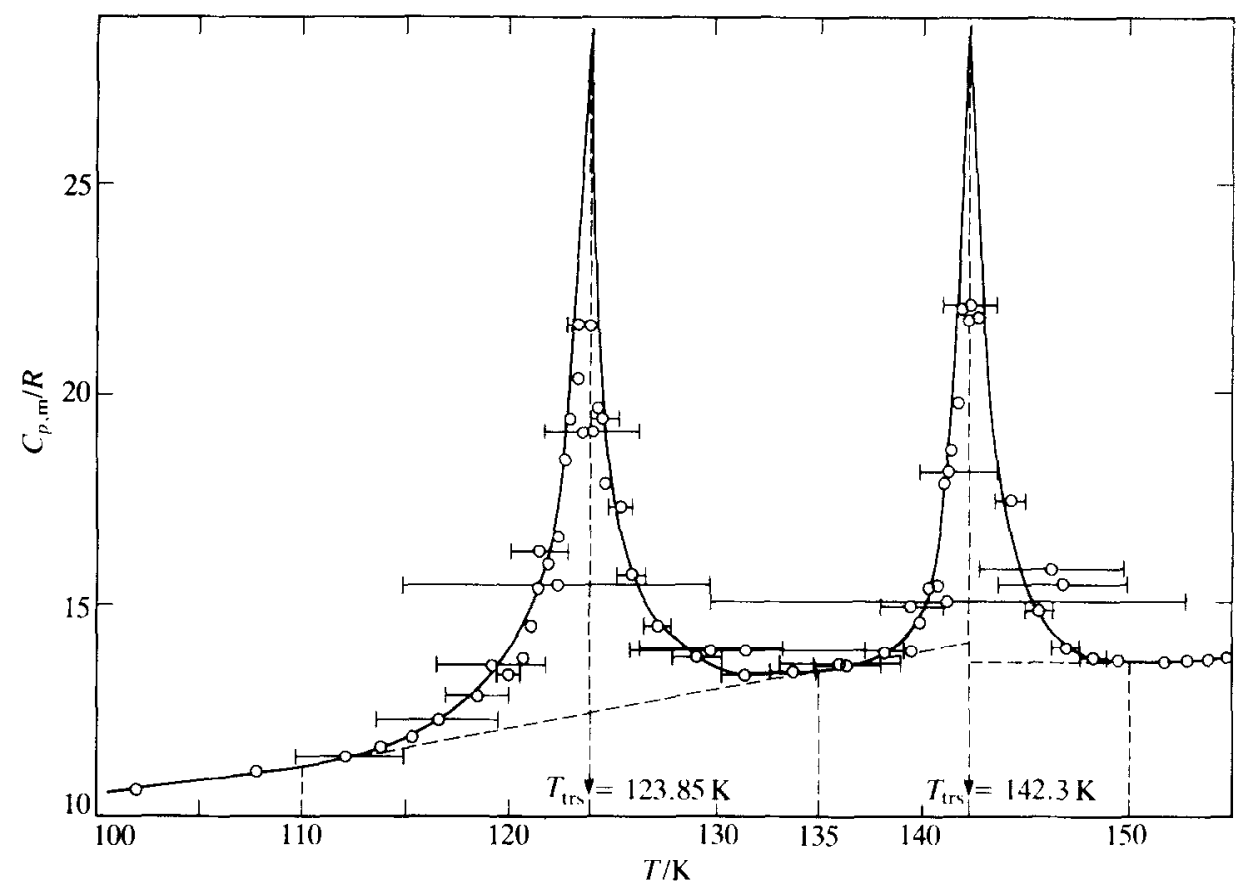

FIGURE 3. An expanded plot of experimental heat capacities of potassium $n$-butanoate through the IV $\rightarrow$ III transition region showing the temperatures of transition, the arbitrary lattice lines, and the regions over which extrapolations were made. Horizontal bars indicate the extent of enthalpy-type determinations.

TABLE 4. Enthalpy and entropy of $142.3 \mathrm{~K}$ transition in potassium $n$-butanoate $\left(R=8.3144 \mathrm{~J} \cdot \mathrm{K}^{-1} \cdot \mathrm{mol}^{-1}\right) ; N$ denotes the number of determinations

\begin{tabular}{|c|c|c|c|c|c|c|}
\hline & $N$ & $T_{1} / \mathrm{K}$ & $T_{2} / \mathrm{K}$ & $\Delta_{T_{1}}^{T_{2}^{2}} H_{\mathbf{m}} /(\boldsymbol{R} \cdot \mathbf{K})$ & $\Delta_{135 \mathrm{~K}}^{150 \mathrm{~K}} H_{\mathrm{m}} /(\boldsymbol{R}$ & K) $\Delta_{135 \mathrm{~K}}^{150 \mathrm{~K}} S_{\mathrm{m}} / R$ \\
\hline \multicolumn{7}{|c|}{$\mathrm{II} \rightarrow \mathrm{I}$ Ttransition $(142.3 \mathrm{~K})$} \\
\hline Series III & 3 & 133.17 & 149.92 & 261.17 & 238.0 & \\
\hline Series IV & 1 & 129.68 & 152.73 & 346.41 & 238.1 & \\
\hline Series V & 8 & 134.83 & 150.15 & 241.92 & 237.6 & \\
\hline Series VIII & 12 & 137.21 & 149.76 & 203.49 & 236.5 & \\
\hline \multicolumn{5}{|c|}{ Graphical integration } & $237.3^{a}$ & 1.664 \\
\hline \multicolumn{4}{|c|}{ Lattice contribution (estimated) } & mean: & $\begin{array}{r}237.5 \\
-205.0 \\
\end{array}$ & 1.438 \\
\hline \multirow{2}{*}{\multicolumn{4}{|c|}{ Graphical integration }} & $\Delta_{\mathrm{trs}} H_{m} /(R \cdot \mathrm{K})$ & 32.5 & \multirow{2}{*}{0.226} \\
\hline & & & & $\begin{array}{l}\Delta_{\mathrm{trs}} S_{\mathrm{m}} / R \\
\Delta_{\mathrm{trs}} H_{\mathrm{m}} /(R \cdot \mathrm{K})\end{array}$ & 32.3 & \\
\hline
\end{tabular}

${ }^{a}$ Not included in mean value. 


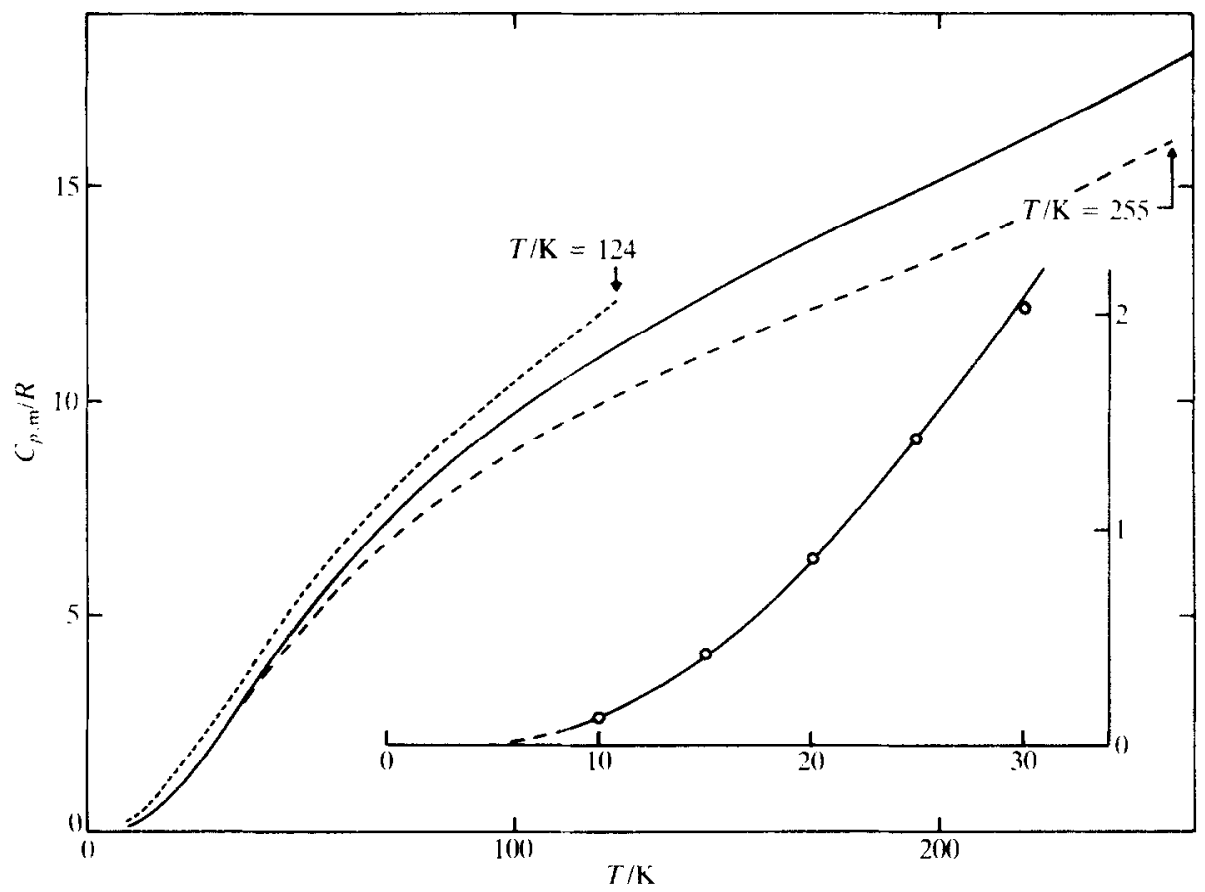

FIGURE 4. Comparison of $C_{p, m}$ taken in the low-temperature region: $--\cdots, 0$, potassium propanoate: - - isobutanoate;,$--- n$-butanoate.

TABLE 5. Subambient phase transitions (trs) of potassium $n$-butanoate; comparison between present and previous $^{(3)}$ results $^{a}$

\begin{tabular}{|c|c|c|c|c|}
\hline trs & $T_{\mathrm{trs}} / \mathrm{K}$ & $\Delta_{\mathrm{lrs}} S_{\mathrm{m}} / R$ & $\Delta_{\mathrm{trs}} S_{\mathrm{m} . \text { cum }} / R$ & Method \\
\hline $\begin{array}{l}\text { IV B } \rightarrow \text { IV A } \\
\text { IV A } \rightarrow \text { III B } \\
\text { III B } \rightarrow \text { III A }\end{array}$ & $\begin{aligned} & 123.85 \\
& 142.3 \\
\approx & 250\end{aligned}$ & $\begin{array}{r}0.400 \\
0.266 \\
-\quad b\end{array}$ & 0.626 & $\begin{array}{c}\text { adiabatic calorimetry } \\
\text { (this work) }\end{array}$ \\
\hline $\begin{array}{l}\text { IV B } \rightarrow \text { IV A } \\
\text { IV A } \rightarrow \text { III B } \\
\text { III B } \rightarrow \text { III A }\end{array}$ & $\begin{array}{c}123 \pm 2 \\
143 \pm 2 \\
-c\end{array}$ & $\begin{array}{l}-- \\
-\cdots \\
-\end{array}$ & 0.6 & d.s.c. ${ }^{[3\}}$ \\
\hline
\end{tabular}

"Phase designation according to scheme (2).

${ }^{b}$ Not evaluable (see text).

' Escaped d.s.c. analysis.

TABLE 6. Comparison of potassium $n$-butanoate enthalpy-type determinations with integrated smoothed heat-capacity curves $\left(R=8.3144 \mathrm{~J} \cdot \mathrm{K}^{-1} \cdot \mathrm{mol}^{-1}\right)$

\begin{tabular}{cccccc}
\hline & $T_{1} / \mathrm{K}$ & $T_{2} / \mathrm{K}$ & $\Delta H_{\mathrm{m}} /(R \cdot \mathrm{K})$ & $\int\left(C_{p, \mathrm{~m}} / R\right) \mathrm{d} T$ & $10^{2} \delta \Delta H_{\mathrm{m} /} / \Delta H_{\mathrm{m}}$ \\
\hdashline & & & & \\
$\mathrm{A}$ & 162.09 & 200.21 & 562.09 & 562.4 & 0.06 \\
$\mathrm{~B}$ & 186.80 & 205.09 & 281.05 & 281.67 & 0.22 \\
$\mathrm{C}$ & 69.34 & 113.62 & 425.79 & 425.33 & 0.11 \\
\hline
\end{tabular}


TABLE 7. Molar thermodynamic functions of potassium $n$-butanoate:

$$
R=8.3144 \mathbf{J} \cdot \mathbf{K}^{-1} \cdot \mathrm{mol}^{-1} ; \quad \Phi_{\mathrm{m}}^{\prime \prime}(T, 0) \stackrel{\text { def }}{=}-\Delta_{0}^{T} H_{\mathrm{m}}^{\prime \prime}(T) / T+\Delta_{0}^{T} S_{\mathrm{m}}(T)
$$

\begin{tabular}{|c|c|c|c|c|c|c|c|c|c|}
\hline$T / \mathrm{K}$ & $C_{p, \mathrm{~m}} / R$ & $\Delta_{0}^{T} S_{\mathrm{m}}^{\circ} / R \Delta$ & ${ }_{0}^{T} H_{\mathrm{m}}^{\circ} /(R \cdot \mathrm{K})$ & $\Phi_{\mathrm{m}}^{\circ}(T, 0) / R$ & $T / \mathrm{K}$ & $C_{p, \mathrm{~m}} / R$ & $\Delta_{0}^{\mathrm{T}} S_{\mathrm{m} / 1}^{\prime}$ & $\Delta_{0}^{\mathrm{T}} H_{\mathrm{m}}^{*} /(R$ & K) $\Phi_{m}^{\prime}(T, 0) / R$ \\
\hline 0 & 0 & 0 & 0 & 0 & & {$[13.40]$} & {$[12.28]$} & [929.50] & {$[5.39]$} \\
\hline 10 & 0.249 & 0.083 & 0.623 & 0.021 & 140 & 14.65 & $(13.18)$ & $(1046.90)$ & $(5.70)$ \\
\hline 15 & 0.690 & 0.260 & 2.885 & 0.068 & & {$[13.83]$} & {$[12.78]$} & {$[997.50]$} & {$[5.66]$} \\
\hline 20 & 1.277 & 0.537 & 7.761 & 0.149 & $142.3^{h}$ & $(\approx 23.85)$ & (13.40) & $(1078.94)$ & $(5.82)$ \\
\hline 25 & 1.931 & 0.891 & 15.761 & 0.261 & & {$[14.03]$} & {$[13.00]$} & {$[1029.54]$} & {$[5.77]$} \\
\hline 30 & 2.629 & 1.305 & 27.146 & 0.400 & \multirow{2}{*}{\multicolumn{5}{|c|}{ Phase I }} \\
\hline 40 & 4.059 & 2.258 & 60.63 & 0.742 & & & & & \\
\hline 50 & 5.404 & 3.310 & 108.04 & 1.149 & \multirow[t]{2}{*}{$142.3^{b}$} & $(\approx 23.85)$ & (13.63) & (1111.36) & (5.82) \\
\hline 60 & 6.656 & 4.407 & 168.38 & 1.600 & & {$[13,6]$} & {$[13.00]$} & [1029.54] & [5.77] \\
\hline 70 & 7.737 & 5.517 & 240.55 & 2.081 & \multirow[t]{2}{*}{145} & 15.38 & (13.89) & (1148.21) & $(5.97)$ \\
\hline 80 & 8.716 & 6.614 & 322.80 & 2.579 & & {$[13.60]$} & {$[13.26]$} & {$[1066.26]$} & {$[5.91]$} \\
\hline 90 & 9.627 & 7.695 & 414.66 & 3.088 & \multirow[t]{2}{*}{150} & $13.60^{\circ}$ & (14.35) & $(1216.21)$ & $(6.24)$ \\
\hline 100 & 10.445 & 8.752 & 515.0 & 3.601 & & {$[13.60]$} & {$[13.72]$} & {$[1134.26]$} & {$[6.16]$} \\
\hline \multirow[t]{2}{*}{$110^{a}$} & 11.192 & $(9.78)$ & $(623.25)$ & $(4.12)$ & 160 & 13.91 & 15.24 & $(1353.40)$ & 6.78 \\
\hline & [11.19] & {$[9.78]$} & [623.25] & {$[4.12]$} & 170 & 14.34 & 16.09 & 1494.7 & 7.299 \\
\hline \multirow[t]{2}{*}{115} & 11.83 & $(10.29)$ & $(680.00)$ & $(4.38)$ & 180 & 14.75 & 16.92 & 1640.2 & 7.811 \\
\hline & [11.58] & {$[10.29]$} & {$[680.00]$} & [4.38] & 190 & 15.18 & 17.73 & 1789.8 & 8.312 \\
\hline \multirow[t]{2}{*}{120} & 13.63 & (10.79) & $(739.00)$ & $(4.63)$ & 200 & 15.60 & 18.52 & 1943.7 & 8.803 \\
\hline & {$[12.03]$} & {$[10.79]$} & [739.00] & [4.63] & 210 & 16.00 & 19.29 & 2101.7 & 9.284 \\
\hline \multirow[t]{4}{*}{$123.85^{b}$} & $(\approx 24.1)$ & $(11.17)$ & $(785.96)$ & $(4.82)$ & 220 & 16.37 & 20.04 & 2263.5 & 9.756 \\
\hline & \multirow{3}{*}{\multicolumn{3}{|c|}{ Phase II }} & {$[4.82]$} & 240 & 17.16 & 21.50 & 2598.7 & 10.675 \\
\hline & & & & & 260 & 17.98 & 22.91 & 2950.3 & 11.562 \\
\hline & & & & & 280 & 18.53 & 24.26 & 3315.8 & 12.421 \\
\hline \multirow[t]{2}{*}{123.85} & $(\approx 24.1)$ & (11.57) & $(835.99)$ & (4.82) & 298.15 & 19.00 & 25.44 & 3656.0 & 13.178 \\
\hline & {$[12.37]$} & [11.17] & [785.96] & {$[4.82]$} & 300 & 19.06 & 25.56 & 3691.2 & 13.254 \\
\hline \multirow[t]{2}{*}{130} & 13.48 & (12.18) & (913.15) & (5.16) & 320 & 19.90 & 26.81 & 4080.6 & 14.063 \\
\hline & [12.93] & {$[11.78]$} & [863.75] & {$[5.14]$} & 340 & 20.74 & 28.05 & 4486.9 & 14.849 \\
\hline $135^{a}$ & 13.40 & (12.68) & $(978.90)$ & $(5.43)$ & 350 & 21.21 & 28.65 & 4596.8 & 15.23 \\
\hline
\end{tabular}

${ }^{a}$ Quantities in parentheses represent either estimated heat capacities or thermodynamic functions on the arbitrary assumption that the transitions are truly isothermal at the transition temperature indicated.

${ }^{b}$ Quantities in square brackets represent selected lattice heat capacities or the integrated thermodynamic functions of the selected lattice.

this point, as soon as complete thermophysical information up to the melt region is available on lithium and potassium, as well as on sodium $n$-butanoates.

Equilibrium measurements (see the expanded plot of figure 3) show that the peaks of the bifurcated transition, which appeared partially overlapping in the d.s.c. traces, ${ }^{(3)}$ are satisfactorily separated. Accordingly, a separate enthalpy and entropy change can be calculated for each peak (see tables 3 and 4 for the peaks at $123.85 \mathrm{~K}$ and $142.3 \mathrm{~K}$, respectively; calculations were performed assuming isothermal transition for each peak, as shown in figure 3).

The sub-ambient phase relations of potassium $n$-butanoate can be detailed as follows:

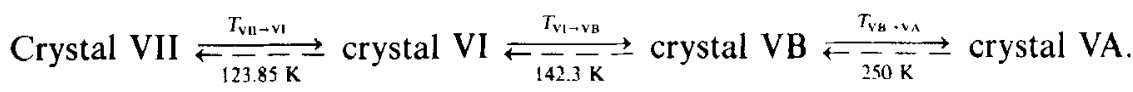


The relevant present and previous ${ }^{(3)}$ d.s.c. results are compared in table 5 . When allowance is made for the combined accuracies of the techniques, the agreement can be considered to be satisfactory.

In table 6, enthalpy-type measurements are compared with the values obtained by integrating the corresponding heat capacity curves. Smoothed thermodynamic functions at selected temperatures (up to $350 \mathrm{~K}$ ) are shown in table 7 .

Finally, the heat capacities of the low-temperature phases of potassium propanoate, ${ }^{(1)}$ isobutanoate, ${ }^{(2)}$ and $n$-butanoate are compared in figure 4 . It is interesting (see the lower right-hand corner of the figure, where the circles refer to propanoate, and the unbroken curve to isobutanoate) that at $T / \mathrm{K}<30$ the heat capacities of the propanoate and isobutanoate are practically undistinguishable, whereas that of isobutanoate is within about 10 per cent of that of the $n$-butanoate at the upper end of the stabilization range of the latter. However, the greater molecular freedom of the latter eventually leads to large values.

\section{REFERENCES}

1. Franzosini, P.: Westrum. E. F.. Jr. J. Chem. Thermodynamic's 1984, 16. 81.

2. Franzosini, P.; Westrum. E. F.. Jr. J. Chem. Thermodynamics 1984, 16. 127.

3. Ferloni, P.: Sanesi, M.; Franzosini, P. Z. Naturforsch. 1975, 30a, 1447.

4. Ferloni, P.; Spinolo, G.: Zangen, M.: Franzosini, P. Z. Naturforsch. 199, 32a, 329.

5. Sanesi, M.; Ferloni, P.; Franzosini, P. Z. Naturforsch. 1977, 32a, 1173

6. Cingolani, A.; Spinolo, G.: Sanesi, M.: Franzosini, P. Z. Naturforsch. 1980, 35a. 757

7. Sokolov, N. M. Tezisy Dokl. X. Nauch. Konf. S.M.I. 1956.

x. Sokolov, N. M.; Pochtakova, E. I. Zh. Obshich. Khim. 1958, 28, 1693.

9. Schiraldi, A : Chindelli, G. J. Phys E. Sci. Instr. 1977, 10, 596.

10. Ngeyi, S. P.: Westrum, E. F., Jr.; Franzosini. P. J. Chem. Thermodynamics 1986, 18, 609.

11. Westrum. E. F.. Jr. Proceedings NATO Advanced Study Institute on Thermochemistry at Viana du Castello, Portugal. Riberio da Silva, M. A. V.: editor. Reidel. New York. 1984, pp. 745-776.

1 2. Franzosini, P.: Plautz, W. A.; Westrum, E. F., Jr. J. Chem. Thermodynamics 1983, 15, 445

13. Franzosini, P.: Ngeyi, S. P.: Westrum, E. F., Jr. J. Chem. Thermodynamics 1986, 18, 1169

14. Michels, H. J.; Ubbelohde, A. R. J. Chem. Su. Perkin II 1972, 1879. 